\title{
RTs across Dual Stimuli, Gender, GPA and Trial-Type
}

\author{
Hartanto $^{1}$ \\ Fakultas Psikologi Universitas Widya Dharma
}

\begin{abstract}
This psychophysics experiment of Eriksen Flanker Task experiment is built on four independent variables (stimuli, gender, GPA, and trial-type) with one dependent variable (RTs). CAF was also examined between stimuli arrow and letter. The data was analysed using four-way ANOVA. The result revealed that 1) Arrow stimuli needed few RTs than letter stimuli $(\mathrm{F}$ value $=17.964$, and $\mathrm{p}$-value $=2.34 \mathrm{e}-05) .2$ ) In gender, there was a significantly different effect of RTs between female and male groups (F value $=91.203$, pvalue $=2 \mathrm{e}-16(\mathrm{p}<0.001) .3)$ In trial-type, incongruent trial required more RTs than congruent trial $(\mathrm{F}$ value $=144.569, \mathrm{p}$-value $=<2 \mathrm{e}-16(\mathrm{p}<0.001) .4)$ Arrow stimuli was more accurate than letter with $\mathrm{t}$-value $=6.4099, \mathrm{df}=2220.5, \mathrm{p}$-value $=1.773 \mathrm{e}-10$. The result found the differences between the stimuli were caused by horizontal and vertical attention, so were in trial-type with parallel and focus phase. Across gender, the male group has proven to be faster in both stimuli than the female counterpart. This RTs pattern suggests that in conflict flanker task research, people tend to show the same architecture processing. Therefore, the finding is quite universal in several researches.
\end{abstract}

Keywords: CAF; flanker effect; flanker task

Object recognition, object repetition and focus attention have an essential role in learning patterns of a human being through evolution. Some stimulus would be ignored and fades away, but some of them are straight forward and have a typical response (selective visual attention). The stimulus may also have a different pattern of response between gender and various type of stimuli, especially in reaction time (RTs). One of the visual attention tests that has a purpose for determining the reaction time with the level of compatibility distraction stimulus is Flanker Task (Stins, Polderman, Boomsma, \& Geus, 2007). Coined initially from Barbara Eriksen and Charles W Eriksen cognitive work

\footnotetext{
1 Address for corespondence:

hartantopaud@unwidha.id
}

experiment in 1974. Flanker Task primary work is to explain the ability of attention focus from distraction stimulus with taskrelevant and task-irrelevant flankers, whereas the distraction stimulus is a set of stimulus which has a quite different directional from the target (Wells \& Hamm, 2009). Therefore responses that are inappropriate would be suppressed, ideally. Thus, flanker effect refers to the difference in mean of RTs of response congruent trial stimulus and incongruent trial stimulus (distraction) (Mordkoff, 1996; Wright, 2015).

Flanker effect has recently gained attention in research focus for several years because it is dynamic, applicable in many domains, and has various result benefits (detects cognitive degeneration that is caused by drugs, unhealthy lifestyle, and neurological disorders) 
(McLean et al., 2013; Atmaca, Sebanz, \& Knoblich, 2011; Chen et al., 2015). Many flanker task researched have been conducted through the years with various kinds of approaches. As with the emotion recognition, Zhou and Liu (2013) developed task-relevant and irrelevant flankers to modulate the emotion response. Bugg (2014) has a different approach with flanker task method, that is to examine contingency-driven ISPC (Item-Specific Proportion Congruence) and control-driven ISPC. ISPC refers to the minimalized effect interference for the incongruent item to congruent item. This phenomenon was also studied under two different stimuli (letter and arrow). Rouder and King (2003) suggested that negative and positive flanker task might yield a different result. Therefore, in a current research, I will use flank symbol ("<", ">") and letter ("N", "H") to deploy the flanker experiment in two conditions. The "H" and "N" letters have the same height and almost similar to each other, which make them perfect for studying selective attention in conflict task. In addition, Jain, Bansal, Kumar, and Singh (2015) conclude that several variables settle the differences in RTs. The result suggests that various RTs were fazed by personality type, genders, ages, and intellectuality. Consequently, to address this question, an experiment is needed to initiate the measurement of RTs across genders, GPA, trial-type and with the different model stimuli.

Widely known, even volunteer's responses have particular navel in the central nervous system. ACC (Anterior Cingulate Cortex) has been studied through years and revealed to become the central to an automatic response. When a participant faces a conflict task, ACC would be activated for some periods.
According to Baars and Gage (2013) ACC plays vital role to generate an incongruent response in flanker task. In neurological basis, ACC is responsible for autonomic function patterns. Gratton (Stins, et al., 2007), studied and named this pattern as the Gratton effect. Gratton effect describes the lower interference effect following incongruent trial compare to the congruent trial (Blais, Stefanidi, \& Brewer, 2014). Lower interference effect (congruency effect) emerged because the ACC becomes activated after the incongruent trial presents then in the result, the response becomes more cautious and controlled, compared to the following congruent trial. Therefore, Gratton effect also can be defined as the size of differences RTs between both trials which are larger subsequent to the congruent than the incongruent (sequential dependent effect) (Hazeltine \& Mordkoff, 2014). In other perspectives: flanker effect is typically smaller in different-series stimuli (inconsistent), than to stimuli that are not inconsistent. To illustrate, pattern error correlation that emerged from error administrating item questionnaire in psychometric properties would be similar. Sequential dependent effect arose due to expectancies-series stimuli in flanker task, which is increasing alertness of the participant to accomplish the task respectively. Ghinescu, Schachtman, Ramsey, Gratton, and Fabiani (2016), found that SDE has been associated with the prepared reflex control cognitive in daily life such as driving and studying and was modulated by conflict adaptation.

Flanker Task was principally designed to test volunteer and also non-volunteer responses. These responses made a pattern that explains tendency about how to perceive stimuli, so to speak, these reactions would draw a specific pattern 
with certain accuracy. CAF (Conditional Accuracy Functional) was used to measure the accuracy pattern trial from both stimuli. The current study is segmented into four main points; 1 ) this experiment is deployed in two block phases, each event/block trial will carry two different stimuli. Flanker symbol compares to letter stimuli to discover the RTs among participants. To assume, culturally, a symbol (flank) would be recalled at first before a letter, so there is a shred of evidence to support that the symbol perceived universal and reminded more natural than the letter (Shiraev \& Levy, 2010) and how the brain functions differently (Carreiras, Quinones, Hernandez-Cabrera \& Dunabeitia, 2015). 2) Previous research has shown that genders are differentially affected by distractors (Judge \& Taylor, 2008). The different RTs responses between men and women will be analyzed and assumed that women have more upsurge time, less accuracy and more distracted (error) than men. It can be seen that men might develop techniques that are different from their rivals (Adam et al., 1999). Moreover, gender RTs will be sorted by GPA level. GPA levels were divided into two groups that are above $3.3(>3.3)$ and below 3.3 $(<3.3)$. The participant who has higher level GPA score in less RTs than its rival. Proper visual attention, robust concentrate and habituation to pore played a significant role. 3) In the third question, the trial-type will analyze to distinguish which RTs is faster between the congruent and incongruent trial in two different stimuli. 4) Finally, CAF effect has become a vast majority topic in -mostly- every Flanker task research, thereby additionally, to this end it was decided to analyze RTs CAF for both trial stimuli. The CAF is only limited to measure between trial-type (congruent - incongruent) across the stimuli. As with the growing up IT and open source programming used in interdisciplinary science, it has given us more benefits in Psychology particularly Cognitive Neuroscience for supporting methods and data analyzed in research (Anderson, 2014).

\section{Method}

Participants of this research were 53 healthy Javanese Widya Dharma University undergraduate students ranging from the fifth to seventh semester. All of the participants fill the informed consent contract in regards to this research beforehand. All participants were righthanded and had a good visualization. The age of the participants were ranging from $21-25$ years old.

Two kinds of stimuli were presented on the computer screen. Stimuli in flanker task build up using Python Expyriment (Krause \& Lindemann, 2014; Marsja, 2017; Dalmaijer, Mathôt, \& der Stigchel, 2014) with certain modification. Participants sat approximately $30 \mathrm{~cm}$ from the monitor screen and instructed to the fixation point in the monitor center. Two computers are used in two separate classes for the experiment, in such a way to avoid covert observation competition among the participants (Zhu, Zhou, \& Ye, 2016). First, stimulus with an arrow was presented around $1000 \mathrm{~ms}("<<<<<, ~>>>>>, \quad<<<<<$, $>>>>")$, then the cue stimuli with combine letter ("HHHHH, $\mathrm{HHNHH}, \mathrm{NNNNN}$, NNHNN"). The target stimulus was in the center, and other letters were used as distractors. Details about the instruction flanker test had been presented on the computer screen before the participants initiated the experiment. The data was saved in Python folder then stored and exported in $\mathrm{R}$ to proceed analysis. The 
research was done in class early, to support the valid result. This experiment contained six blocks with 24 trials total, so there will be 360 total trials for each block.

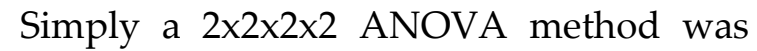
used and t-test analysis to perform the analysis. The details are $2 \times 2$ (stimuli: flanker stimuli vs letter stimuli), $2 \times 2$ (participant group: female vs male), $2 \times 2$ (GPA group: $>3.3$ vs <3.3) and $2 \times 2$ (trialtype: congruent vs incongruent) (table 1 ) and t-test analysis to determine the accuracy of the stimuli. Due to the lack of information about how many flanker trials standard can be done, the decision was made to have a very brief discussion about the endurance of the participants to execute the flanker task.

\section{Result}

From the aggregate of 53 flanker data set, there were four individual datasets which were considered inadequate and therefore were excluded from being analyzed due to the significant error rates $(60-100 \%$ error

Table 1.

IV, DV and subject per block formation

\begin{tabular}{|c|c|c|c|c|}
\hline \multirow{2}{*}{\multicolumn{3}{|c|}{$\begin{array}{c}\text { Flanker/Gender/ } \\
\text { GPA }\end{array}$}} & \multicolumn{2}{|c|}{ Trial-type } \\
\hline & & & Congruent & Incongruent \\
\hline \multirow{4}{*}{ Arrow } & \multirow{2}{*}{ M } & $\begin{array}{l}\text { Male A } \\
(>3.3)\end{array}$ & $\begin{array}{c}\text { Congruent arrow flanker in } \\
\text { male with GPA above } 3.3 \\
\text { (10 subjects })\end{array}$ & $\begin{array}{l}\text { Incongruent arrow flanker male } \\
\text { with GPA above } 3.3 \\
\text { (10 subjects) }\end{array}$ \\
\hline & & $\begin{array}{c}\text { Male B } \\
(<3.3)\end{array}$ & $\begin{array}{c}\text { Congruent arrow flanker in } \\
\text { male with GPA below } 3.3 \\
\text { (11 subjects) }\end{array}$ & $\begin{array}{l}\text { Incongruent arrow flanker male } \\
\text { with GPA below } 3.3 \\
\text { (11 subjects) }\end{array}$ \\
\hline & \multirow{2}{*}{ F } & $\begin{array}{c}\text { Female A } \\
(>3.3)\end{array}$ & $\begin{array}{l}\text { Congruent arrow flanker in } \\
\text { female with GPA above } 3.3 \\
\text { (14 subjects) }\end{array}$ & $\begin{array}{l}\text { Incongruent arrow flanker in } \\
\text { female with GPA above } 3.3 \\
\text { (14 subjects) }\end{array}$ \\
\hline & & $\begin{array}{c}\text { Female B } \\
(<3.3)\end{array}$ & $\begin{array}{l}\text { Congruent arrow flanker in } \\
\text { female with GPA below } 3.3 \\
\text { (14 subjects) }\end{array}$ & $\begin{array}{l}\text { Incongruent arrow flanker in } \\
\text { female with GPA below } 3.3 \\
\text { (14 subjects) }\end{array}$ \\
\hline \multirow{4}{*}{ Letter } & \multirow{2}{*}{$\mathrm{M}$} & $\begin{array}{c}\text { Male A } \\
(>3.3)\end{array}$ & $\begin{array}{l}\text { Congruent letter flanker in } \\
\text { male with GPA above } 3.3 \\
\text { (10 subjects) }\end{array}$ & $\begin{array}{l}\text { Incongruent letter flanker male } \\
\text { with GPA above } 3.3 \\
\text { (10 subjects) }\end{array}$ \\
\hline & & $\begin{array}{c}\text { Male B } \\
(<3.3)\end{array}$ & $\begin{array}{c}\text { Congruent letter flanker in } \\
\text { male with GPA below } 3.3 \\
\text { (11 subjects) }\end{array}$ & $\begin{array}{l}\text { Incongruent letter flanker male } \\
\text { with GPA below } 3.3 \\
\text { (11 subjects) }\end{array}$ \\
\hline & \multirow{2}{*}{ F } & $\begin{array}{c}\text { Female A } \\
(>3.3)\end{array}$ & $\begin{array}{l}\text { Congruent letter flanker in } \\
\text { female with GPA above } 3.3 \\
\text { (14 subjects) }\end{array}$ & $\begin{array}{c}\text { Incongruent letter flanker female } \\
\text { with GPA above } 3.3 \\
\text { (14 subjects) }\end{array}$ \\
\hline & & $\begin{array}{c}\text { Female B } \\
(<3.3)\end{array}$ & $\begin{array}{l}\text { Congruent letter flanker in } \\
\text { female with GPA below } 3.3 \\
\text { (14 subjects) }\end{array}$ & $\begin{array}{l}\text { Incongruent letter flanker female } \\
\text { with GPA below } 3.3 \\
\text { (14 subjects) }\end{array}$ \\
\hline
\end{tabular}


in both stimuli). With formation: 16 groups divided into 10 males with GPA >3.3, 11 males with GPA <3.3, 14 females in both GPA levels. In total, 2441 stimuli were conducted in this research (1241 in arrow stimuli and 1200 in letter stimuli) and $14.75 \%$ error rates (see table 2). Power test analysis suggests that with the effect size of $0.25, \mathrm{k}=16, \mathrm{p}=0.05$ and power $=0.08$ the sufficient sample in each group is 19. In the effect size of 0.40 , the sufficient sample is 8 , and from the data, the cohen D coefficient is 0.158 with the sufficient sample around 50. However, Cohen benchmark is not a stiff value in social sciences (i.e., Psychology) (Kabacoff, 2011; Durlack, 2005). There should be a baseline formula effect size for the similar-previous research. In addition, both stimuli presented in six blocks with each block contains four trials. Therefore, each subject should have 24 trials. In traditional ANOVA analysis, each subject is responsible for each summated rating data.

Boxplots (stimuli, participant group, and trial-type) were produced to support the result. In Boxplot group gender, the only male group has few outlier data point. Outlier represent the data that lies outside the +1.5 IQR. Nonetheless all the boxplot has completed upper and lower whisker which is normal data and adequate representative sample for this research (Hartanto, 2016).

Table 2.

Percent and frequency

\begin{tabular}{llllllllllll}
\hline & Freq & By \% & & Freq & By $\%$ & & Freq & By $\%$ & & Freq & By\% \\
\hline arrow & 1240 & 50.82 & Block1 & 406 & 16.64 & 0 & 609 & 24.96 & congruent & 1222 & 50.1 \\
letter & 1200 & 49.18 & Block2 & 406 & 16.64 & 1 & 609 & 24.96 & incongruent & 1218 & 49.9 \\
Fem_B & 668 & 27.38 & Block3 & 407 & 16.68 & 2 & 610 & 25.00 & & & \\
Fem_A & 669 & 27.42 & Block4 & 407 & 16.68 & 3 & 613 & 25.08 & & & \\
Male_B & 551 & 22.58 & Block5 & 406 & 16.64 & 0(accuracy) & 360 & 14.75 & & & \\
Male_A & 552 & 22.62 & Block6 & 408 & 16.72 & 1(accuracy) & 2080 & 85.25 & & & \\
\hline
\end{tabular}

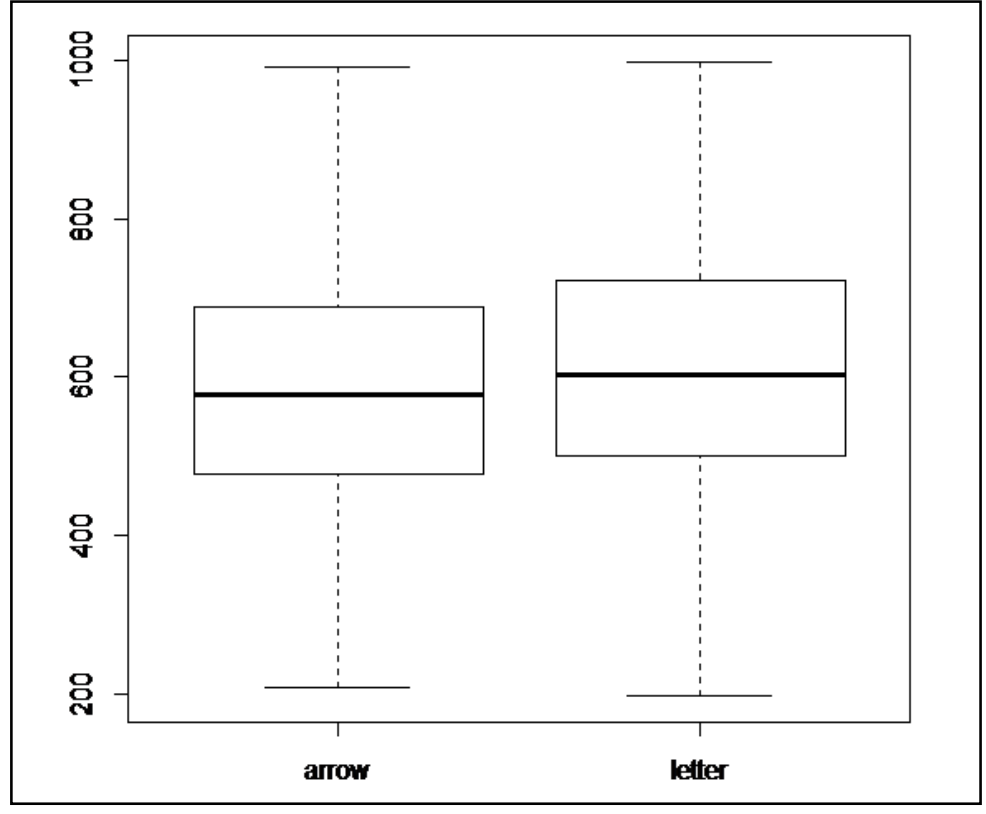

Figure 1. Boxplot Arrow and Letter Stimuli 


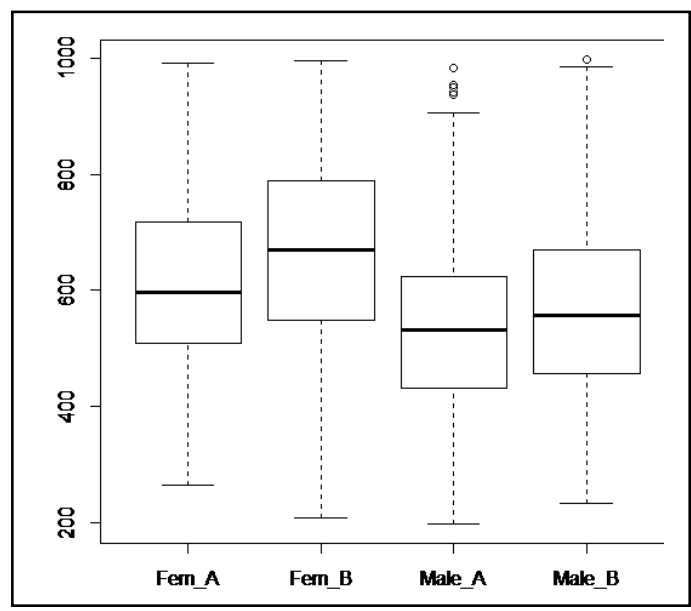

Figure 2. Boxplot Group Gender

1) The four-way ANOVA uncovers more profound information effect in regards to the flanker's data. There was a main overall effect of the stimuli with $F$ value $=17.964$, and $\mathrm{p}$-value $=2.34 \mathrm{e}-05(\mathrm{p}<$ $0.001)$, diff $=25.751$, lower point $=13.837$ and upper $=37.665$ which indicates the performance in the arrow stimuli has required fewer RTs than the letter stimuli. For further reasons, interviews were carried out with some participants about the two kinds of stimuli, and for them, symbol refers to the letter (symbol to the letter) and are easier to maintain than the letter to letter reaction. Because letter to letter was little difficult to bear in mind for some periods, therefore many data point fall over in the few last bin. 2) Later on, there was evidence of effect between the groups of female and male participants, in which ANOVA result has $\mathrm{F}$ value $=91.203$, $\mathrm{p}$-value $=2 \mathrm{e}-16(\mathrm{p}<0.001)$. It indicates that there was a significantly different effect RTs between overall female and male groups, in which male group possess fewer RTs than female group. Sorted by GPA, Tukey analyzed that male A group had the highest effect by means it has fewer reaction times among all groups with diff score $=-32.53177, \mathrm{p}=0.00189(\mathrm{p}<$ 0.001 ). Group of male A attends to execute

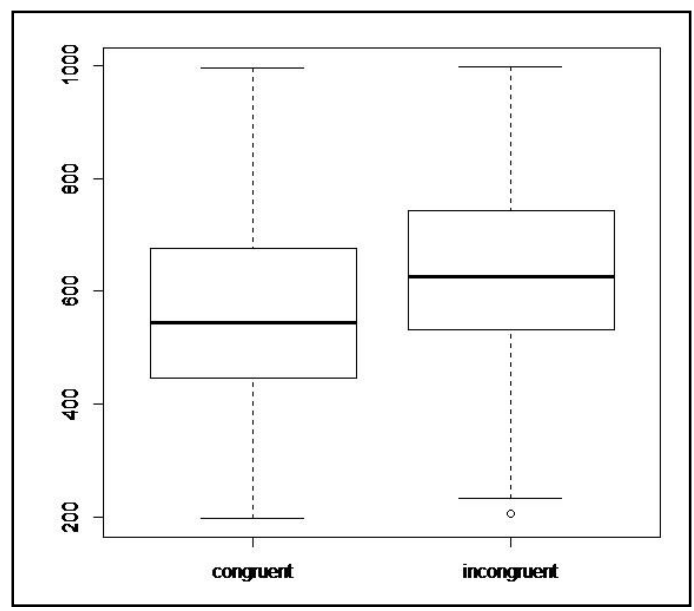

Figure 3. Boxplot Congruent VS Incongruent

a command or decision after very brief tasks presented on the computer screen; they show their self-confidence after the mental accounting has been made respectively. Subsequently, some interviews were implemented with the female A group; they confesssed to make sure or re-check about decisions to be made. In this phase, it was believed that cognitive control was more prone to females than their male counterpart, not just because gender plays an important role, but again, culture has it for years that Javanese females must possess main traits or attitudes in regards to being calm, slow but sure and conscientiously. Male B group has less RTs than female groups but produces more error rates ( $\operatorname{diff}=-46.24783$, lwr $=-68.43842$, upp $=-24.057249, \mathrm{p}=$ $0.0000006 ; p<0.001)$. Group of female B posses the most RTs compare to the other groups $($ diff $=54.52961$, lwr $=75.62765$, upp $=33.431575, p=0.0000000)$. However, in several bins (letter stimuli) the accuracy exceeds females above the group (about $50 \%$ vs. $0 \%$ ) but then overtook by female $\mathrm{A}$ group in 200 - 500 range interval bin (table 3). 3) There was an effect between trialtype with $\mathrm{F}$ value $=144.569$, $\mathrm{p}$-value $=<2 \mathrm{e}-$ $16(\mathrm{p}<0.001)$, diff $=73.04320$, lwr $=$ 61.13039, upp $=84.95565$, that show 
incongruent trial-type which required more RTs compared to the congruent trial. As with the theory explained earlier, the congruent task would be processed with ease than the incongruent task. In the previous result, the congruent task also had more accuracy than the incongruent task, and this phenomenon would be the same across all countries, cultures, and races (Atmaca, et al., 2011). 4) In the case of the detailed result, RTs were separated to equally seven interval bins then input the accuracy percentage index and mean RTs in each bin and- in both stimuli. These steps must be taken to distinguish the CAF value (Bonnet \& Dresp, 1993; Wylie, et al., 2009). However, due to the massive trial multiply with the participant data, there is no way to plot a more subtle CAF graph. Because of that, to accompany plausible explanation, both of the stimuli in this research were presented in two parts of the tables (Table 3). CAF value for arrow stimuli has drawn a pattern that the frequencies in early RTs were less than the late RTs. As well as with the accuracy (see table) in both stimuli. From the table 3, there was evidence in the early bins particularly congruent trial which has more accuracy than its rival and has more frequencies. But as the RTs elevated, the accuracy and rates in both trials and participants are likely do so (below 3.3 and above 3.3).

Table 3.

Accuracy in arrow and letter stimuli

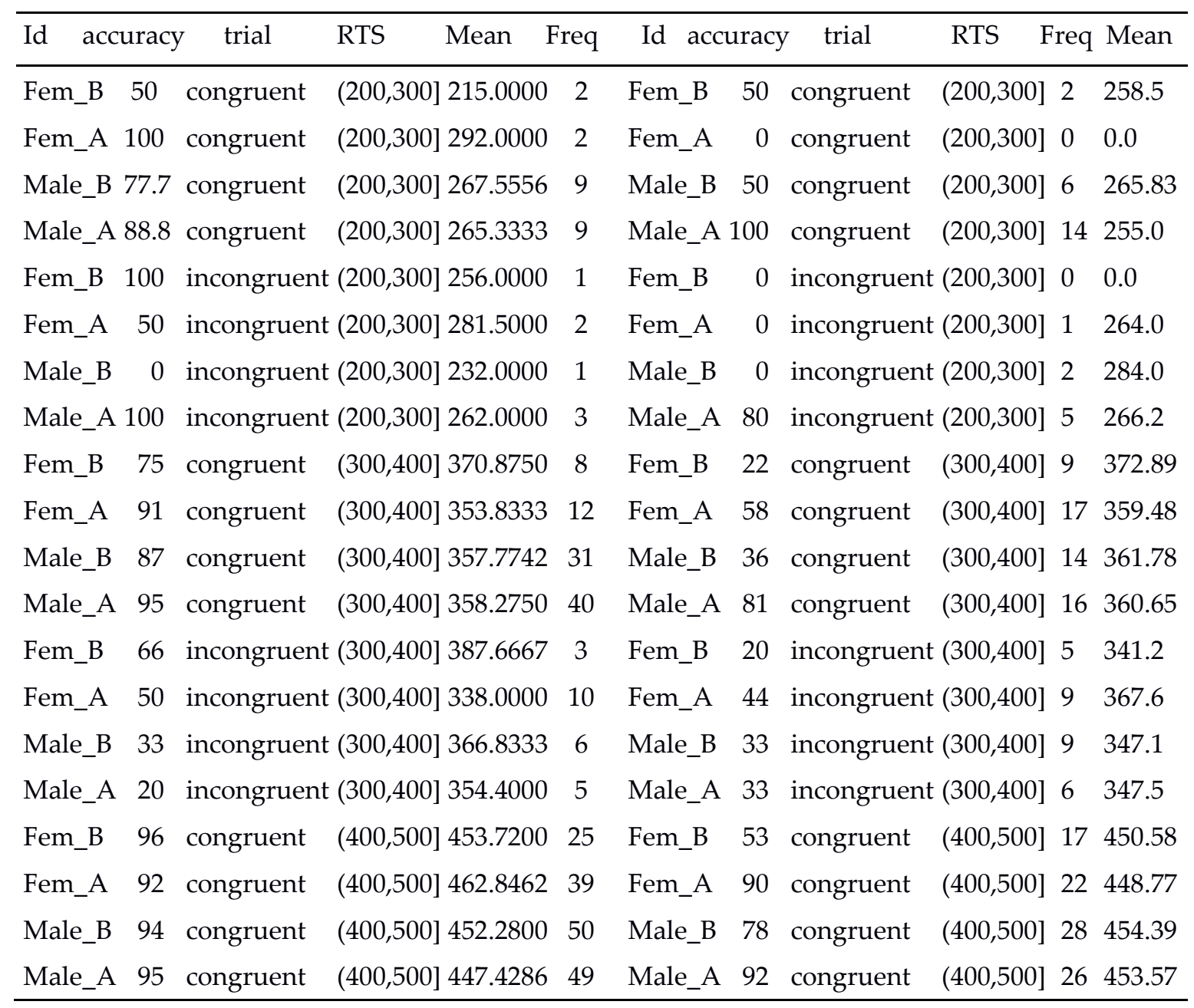




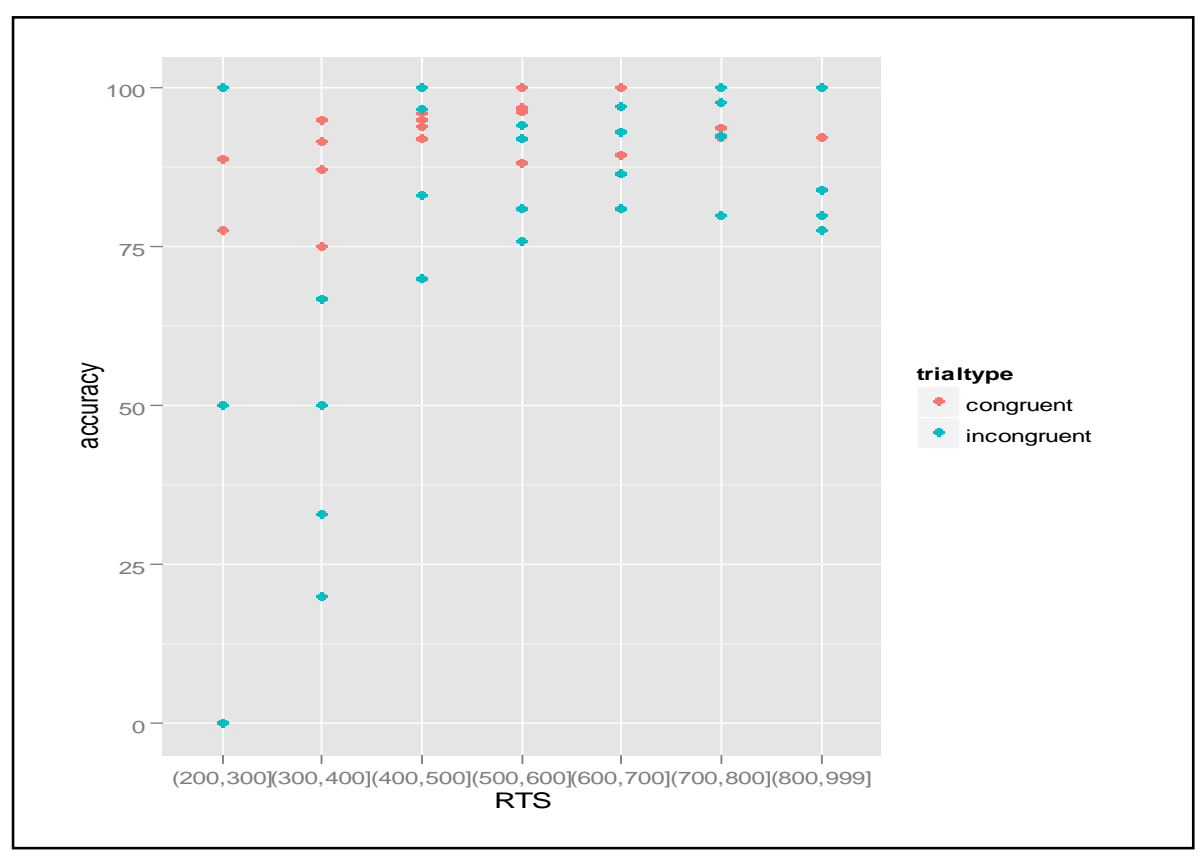

Figure. 4 Arrow CAF Trial-types

The graph (Figure 4) and table give precise information for RTs and the accuracy in each bin for arrow stimuli from the first bin to the last bin. The congruent trial in both groups of female A (>3.3) and female B (<3.3) have slightly different accuracies and frequencies; female A had more attempts to complete the stimuli task. In the male group, the condition is the same, as matter of fact, the male $B$ group did not score any of the tasks in early bin of inconsistent trial (but there is an attempt with 0 accuracies). However, the discrepancies become tighter in both groups in a row with the RTs increased. Mostly, in male B and female B groups, RTs are less accuracy compared to its rivals, by means, these groups have more error rates. In letter stimuli the finding was different, in early bin group of female B score, the $50 \%$ accuracy with two frequencies overtake the rivals with zero rates. Whereas, male $\mathrm{A}$ group leads the scoring task with $100 \%$ accuracy in the congruent task and decline slowly to $80 \%$ in the incongruent task. Table 3 also illustrates the same dynamic RTs to the arrow stimuli, in this case where congruent trial has more accuracy and frequencies than the incongruent task. However the only difference was that letter stimuli has less accuracy in 100\% task, both in the congruent or incongruent task, the male B and A group scored the same accuracy but have different frequencies.

Figure 5 describes RTs vs. accuracy in letter stimuli. Accuracy was low in the early bin but gradually arose then fell over to the last bin. This phenomenon is different compared to arrow stimuli, in which there was no evidence of drop point in the last bins. The interaction between stimuli and group participants was not significant with $\mathrm{p}$-value $=0.14072$, which means there is no effect different from all group participant RTs with different stimuli or in other words after being analyzed, the discrepancies between score groups are tiny/weak to attain approval condition against the null hypothesis. Interaction between stimuli and trial-type 
significant at level $0.00101 ; \mathrm{p}<0.001$. Arrow stimuli score the fastest latency response compared to the letter in both trial-type, with arrow congruent trial is the fastest diff $=98.31753, \quad l w r=76.24549$, upr $=120.38957 \mathrm{p}=0.00 ; \mathrm{p}<0.001$. There was a significant effect interaction between group participant with trial-type (trialtype across arrow and letter stimuli) with $\mathrm{F}$ value $=3.297, \mathrm{p}=0.01968 ; \mathrm{p}<0.05$.
Group of male A with congruent trial have the least RTs compare to other groups, while the group of female B with incongruent trial have the most RTs. Nevertheless, there is an exception in incongruent letter trial with incongruent arrow trial which has reported not significant or there is no different effect in incongruent trial-type RTs between stimuli letter and arrow.

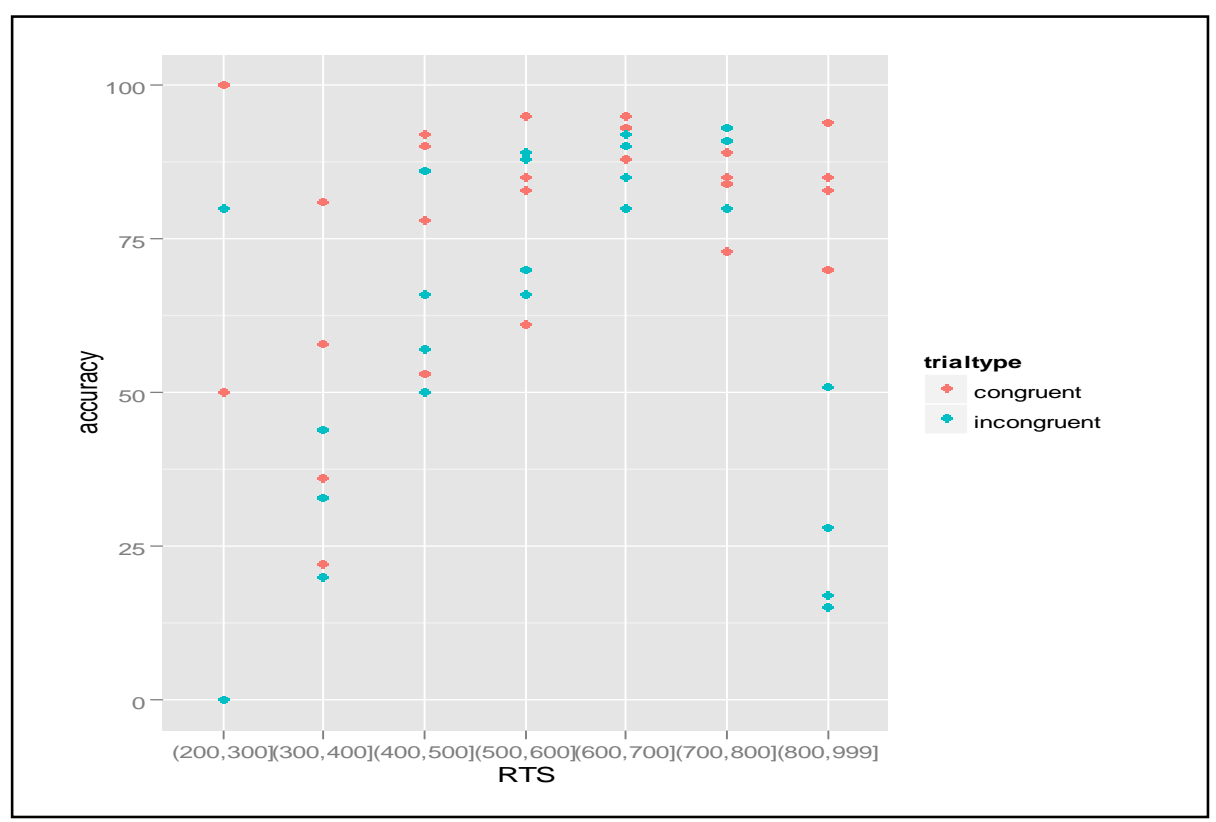

Figure 5. Letter CAF Trial-type

Table 4.

Four way anova

\begin{tabular}{|c|c|c|c|c|c|}
\hline Df & \multicolumn{2}{|c|}{ Sum Sq } & \multirow{2}{*}{$\frac{\text { Mean Sq }}{404407}$} & \multirow{2}{*}{$\frac{\text { F value }}{17.964}$} & \multirow{2}{*}{$\frac{\operatorname{Pr}(>\mathrm{F})}{2.34 \mathrm{e}-05^{* * *}}$} \\
\hline stim & 1 & 404407 & & & \\
\hline participant & 3 & 6159451 & 2053150 & 91.203 & $<2 \mathrm{e}-16^{* * *}$ \\
\hline trial-type & 1 & 3254526 & 3254526 & 144.569 & $<2 \mathrm{e}-16^{* * *}$ \\
\hline stim:participant & 3 & 123150 & 41050 & 1.823 & 0.14072 \\
\hline stim:trial-type & 1 & 243777 & 243777 & 10.829 & $0.00101^{* *}$ \\
\hline participant:trial-type & 3 & 222673 & 74224 & 3.297 & $0.01968 *$ \\
\hline stim:participant:trial-type & 3 & 56675 & 18892 & 0.839 & 0.47227 \\
\hline residuals & 2424 & 545690 & 22512 & & \\
\hline Signif. codes: $0^{‘ * * * \prime} 0.001^{\prime}$ & $01^{\prime * * 1}$ & $5{ }^{\prime \prime} 0.1^{\prime \prime}$ & & & \\
\hline
\end{tabular}


Table 5.

Total mean RTs in 16 groups

\begin{tabular}{lclc}
\hline \multicolumn{1}{c}{ Male Group } & Mean RT & \multicolumn{1}{c}{ Female Group } & Mean RT \\
\hline Congruent Arrow Male $>3.3$ & 455.618 & Congruent Arrow Female $>3.3$ & 581.221 \\
Congruent Arrow Male $<3.3$ & 493.854 & Congruent Arrow Female $<3.3$ & 620.053 \\
Incongruent Arrow Male $>3.3$ & 568.104 & Incongruent Arrow Female $>3.3$ & 637.132 \\
Incongruent Arrow Male $<3.3$ & 623.021 & Incongruent Arrow Female $<3.3$ & 701.042 \\
Congruent Letter Male $>3.3$ & 532.598 & Congruent Letter Female $>3.3$ & 601.672 \\
Congruent Letter Male $<3.3$ & 545.909 & Congruent Letter Female $<3.3$ & 650.321 \\
Incongruent Letter Male $>3.3$ & 589.219 & Incongruent Letter Female $>3.3$ & 638.904 \\
Incongruent Letter Male $<3.3$ & 610.840 & Incongruent Letter Female $<3.3$ & 705.916 \\
\hline
\end{tabular}

Overall, accuracy of t-test analysis found that arrow stimuli have more accuracy than letter with $t=6.4099, \mathrm{df}=2220.5$, $\mathrm{p}$ value $=1.773 \mathrm{e}-10$, mean Arrow $=$ 0.9096774 , mean letter $=0.8216667$.

\section{Discussion}

In this research, totals of 49 participants performed the experiment Flanker Task. 1) In both stimuli, yielded a different result. The arrow trial takes fewer RTs and accuracy than the letter ones- in both trialtypes. In arrow stimulus, the participants used horizontal focus attention to distinguish the target, meanwhile, in letter stimulus, this technique encounters serious difficulties. Because arrows point some direction in left or right used, this method is quite helpful. However, in letter stimulus, letter identification needs vertical focus attention, and just because letter stimulus cannot be read from left to right or vice versa (consonant) thereby it is not pointing to anywhere. Also, letter "H" and "N" have almost similar form and height in mental accounting participants, which elevated double checking behavior vertically.
In complexity stimuli research, using various stimuli is the common technique. Huckauff (Chanceaux, Mathot, \& Grainger, 2014) used rotate flanker stimuli compared to stand upright flanker stimuli; he found that interference in rotate flanker stimuli is higher than the standard stimuli, and therefore costs more RTs and less accuracy. The finding is similar to this research where more complex stimuli presents, needed more RTs than noncomplex stimuli. Bernard and Chung (2011) strengthen the result, state that identification of central stimuli was distracted by level complexity stimuli. The interaction between stimuli and trial-type were also significant. Tukey analyzes reveal that letter stimuli in incongruent trial-type have the most RTs compared to the others. In line with the previous explanation, the letter stimuli in incongruent trial are considered to be the most complicated task in research. In the incongruent trial letter, participants need longer latency response due to the similar strategy takes a few more RTs. Arrow stimuli in the congruent trial, in contrast, scores the fastest RTs. As with Gratton effect and neurological explanation, PFC (prefrontal cortex) is responsible for this 
effect which is modulated by cognitive control (Postle, 2015). 2) In gender group, sort down by GPA group, group of male $\mathrm{A}$ had scored the fastest reaction times in this research, some interviews which were conducted in a male group reveal that: they may learn pattern in a way trials were presented. However, this takes place just for few rounds during when the task comes to an end. The male A group, seems more to be "socially" and "technically" in deciding on the task trial present. Socially, it refers to an ability to decide because they feel understood and credible, whereas technically, it is explained as an ability to determine by calibrating the present stimuli and the prediction probability (i.e., if flanker " $<$ " present twice then ">" will be present next).

The male group seems to have robust and focused their attention more than the female counterpart. From this point of view, due to the difference of hard wire brain among male and female, it unveils that males tend to have a durable state in the highly focusing task (i.e selective and focus attention) (BBC, 2014). Meanwhile, its trait may not or may not fully present in female counterparts (Jant, 2014). Group of female $\mathrm{B}$ give an opinion about task flanker that according to them it has a fast shift and complicated stimuli, contrast to the female A. In addition, they insist that these flanker task trials required more focus attention. Thereby these trials in female $\mathrm{B}$ were considered to be a difficult task which need high perceptual loading (de Fockert, 2013). It was not mentioned which stimuli which was more difficult, because the interaction was not significant. Group of female A considered this flanker task as "the challenging one," according to this finding; therefore it can be concluded that there was a disparity in how they perceive perception and build motivation among the female groups. External motivation is more visible in group of female B, meanwhile female A group is likely to be internally motivated (Ryan, 2009).

3) From ANOVA analysis, the incongruent trial-type has highest RTs compare to all trials. This flanker congruence effect (FCE) finding is similar in several researches (Stins et al., 2007; Hubner \& Lehle, 2007). The interaction between participants and trial-type were also significant, means that according to all participants, incongruent stimuli is considered to be the most challenging part of the stimuli. Participants appear to gather more attention when facing the incongruent trial, and double the re-check behavior which after a few rounds, this behavior becomes "slightly automatic." The automatic phenomenon described by Bugg (2014), involves fast flexibility of cognitive control modulated by attention to the incongruence trial event. Although, after following the incongruent trial the interference effect reduced and readily prepared for the flankers in subsequent trial, however the consequences in fewer RTs with congruent trial fazed by the repetition trial among two choices (Mayr, Awh, \& Laurey, 2003).

4) $\mathrm{CAF}$ graph access the accuracy between two stimuli. Arrow trial has peak accuracy in 300-400 bin RTs and stable for the last bins. The very different condition occurs in the letter trial, of which the point is spread widely in the graphic. Letter trial also has some issue that the accuracy falls over in 700-999 RTs (both trial-types). Performance in the arrow congruent trial was around at $90-100 \%$ accuracy (nearperfect). In letter stimulus, some participants seem cannot maintain the "link-clue" about the target stimuli and press the keyboard as the instruction does (i.e., if 
"H" present press Z keyboard and so with "N" press $M$ in keyboard). After the few last block runs, they nearly-forget the clue. This result also found that participants developed some strategies to encounter the stimuli. If participants focus on the basis to identify the flanker (parallel phase), their accuracy will be near-perfect, but fall below chance in the incongruent trial. The participants in this research seem to use the parallel phase strategy to perform the flanker task. The other approach called focus phase, emphasize on the basis to identify the target stimuli (Hubner, Steinhauser, \& Lehle, 2010). Furthermore, Hubner et al., (2010) inferred that strategies were affected by selective attention in early and late attention towards both stimuli, by means that in early attention, participants just selected and processed one object at a time. In contrast to late attention, which identified several stimuli at a time then picked and processed the target stimuli.

\section{Conclusion}

Flanker task provides abundant information about how human cognition works. Much progress should be made in relation to neurocognitive research, mainly by adding numeric flanker or the eye movement tracking system. Flanker task reveals that different mechanisms occur across stimuli model and gender. In fact, intelligence also settles the difference. However, in mixed stimuli, some of the letters trial fall in the last bins CAFs also unveil the mechanism how participant's respond the task and the result slightly different in both trials.

\section{Suggestion}

Much progress should be made in relation to flanker task research, mainly by adding numeric flanker, Javanese letters or the eye movement tracking system. Also, individu who are living in areas with high level selective attention such as railways and market areas might display different results compared to them who are not.

\section{References}

Adam, J. J., Paas, F. G., Buekers, M. J., Wuyts, I. J., Spijkers, W. A., Wallmeyer, P. (1999). Gender diferences in choice reaction time: Evidence for differential strategies. Ergonomics, 42(2), 327- 335.

Atmaca, S. Sebanz, N. \& Knoblich, G. (2011). The joint flanker effect: Sharing tasks with real and imagined coactors. Exp Brain Res, 211, 371-385. http://doi.org/10.1007/s00221-011-2709$\underline{9}$

Anderson, B. (2014). Computational neuroscience and cognivite modelling. SAGE Publications Inc.

Bernard J. B. \& Chung S. T. L. (2011). The dependence of crowding on flanker complexity and target-flanker complexity. Journal of Vision, 11(8), 116.

Baars, B. J., \& Gage, N. M. (2013). Fundamentals of cognitive neuroscience: A beginner's guide. Elsevier Inc.

Bugg, J. M. (2014). The relative attractiveness of distractors and targets affects the coming and going of itemspecific control: Evidence from flanker tasks. Atten Percept Psychophys, 77, 373-389. http://doi.org/10.3758/s13414014-0752-x.

BBC Horizon. (2014). Is your brain male or female. http://www.bbc.co.uk/ programmes/ b04knbny.

Bonnet, C. \& Dresp, B. (1993). Methods and Design - A fast procedure for 
studying conditional accuracy function. Behavior Research Methods, Instruments, \& Computers, 25, 2-8.

Blais, C. Stefanidi, A. \& Brewer, G. A. (2014). The Gratton effect remains after controlling for contingencies and stimulus repetitions. Frontier in Psychology, 05, 1-11. http://doi.org/10.3389/fpsyg.2014.0120 $\underline{7}$

Carreiras, M., Quinones, I., HernandezCabrera, J. A. \& Dunabeitia, J. A. (2015). Orthographic coding: Brain activation for letters, symbols, and digits. Cerebral Cortex, 25(12), 47484760 .

Chanceaux, M. Mathot, S. \& Grainger, J. (2014). Effects of number, complexity, and familiarity of flankers on crowded letter identification. Journal of Vision, 14(7). http://doi.org/10.1167/14.6.7

Chen, C., Yang, J., Lai, J., Li, H., Yuan, J. \& Abbasi, N. H. (2015). Correlating gray matter volume with individual difference in the flanker interference effect. PLoS ONE, 10(8), doi: $\underline{10.1371 / \text { journal.pone. } 0136877}$

Dalmaijer, E. S., Mathôt, S., \& der Stigchel, S. (2014). PyGaze: An open-source, cross-platform toolbox for minimaleffort programming of eyetracking experiments. Behavior Research Methods, 46(4), 913-921.

Durlack, J. A. (2005). How to select, calculate, and interpret effect sizes. Journal Of Pediatric Psychology, 34(9), 917-928.

de Fockert, J, W. (2013). Beyond perceptual load and dilution: A review of the role of working memory in selective attention. Frontier in Psychology, 04, 112.

Ghinescu, R., Schatchman, T. R., Ramsey, A. K., Gratton, G., Fabiani, M. (2016).
Conflict adaptation and cue competition during learning in an eriksen flanker task. PLoS ONE, 11(12), 1-19. doi: $10.1371 /$ journal.pone.0167119

Hazeltine, E. \& Mordkoff, J. T. (2014). Resolved but not forgotten: Stroop conflict dredges up the past. Frontier of Psychology, 5(1327). http://doi.org/10.3389/fpsyg.2014.0132 $\underline{7}$

Hartanto. (2016). Pengenalan analisis statistik dengan software R. Yogyakarta: Magnum Publishing

Hubner, R. Steinhauser, M. \& Lehle, C. (2010). A dual-stage two-phase model of selective attention. Psychological Review, 117(3), 759-784. http://doi.org/10.1037/a0019471

Hubner, R. \& Lehle, C. (2007). Strategies of flanker coprocessing in single and dual tasks. Journal of Experimental Psychology/Human Perception and Performance, 33(1), 103-123

Jain, A., Bansal, R., Kumar, A., \& Singh, K. D. (2015). A comparative study of visual and auditory reaction times on the basis of gender and physical activity levels of medical first year students. Int J Appl Basic Med Res. 5(2), 124-127. Doi:10.4103/2229-516X.157168

Jant, G. L. (2014, Februari). Brain differences between genders. Retrieved from: https://www.psychologytoday.com/bl og/hope-relationships/201402/braindifferences-between-genders, 30 September 2017

Judge, J. Taylor, P, J. (2008). Gender differences on the semantic flanker task using transposed-letter target words. The Quarterly Journal of Experimental Psychology, 65(10), 2008-2017. doi: $\underline{10.1080 / 17470218.2012 .676654}$

Kabacoff, R. I. (2011). $R$ in action. Shelteer Island: Manning Publications Co. 
Kraus, F. \& Lindemann, O. (2014). Experiment: A Python library for cognitive and neuroscientific experiments. Behav Res, 46, 416-428. doi:

10.3758/s13428-013-0390-6

Marsja, E. (2017, Februari). Python and $R$ as tools of data analysis and building psychological experiments. Retrieved from: https://www.marsja.se/, 19 Juni 2017

Mayr, U., Awh, E., \& Laurey, P. (2003). Conflict adaptation effects in the absence of executive control. Nat, Neurosci. 6, 450-452. doi: 10.1038/ nn1051

Mordkoff, J. T. (1996). Selective attention and internal constraints: There is more to the flanker effect than biased contingencies. In A. F. Kramer, M. G. H. Coles, \& G. D. Logan (Eds.), Converging operations in the study of visual selective attention (pp. 483-502). Washington, DC, US: American Psychological Association. doi: 10.1037/10187-018

McLean, S. P., Garza, J. P., Wiebe, S. A., Dodd, M. D., Smith, K. B., Hibbing, J. R., \& Espy, K. A. (2013). Applying the flanker task to political psychology: A research note. Political Psychology, 20(20). doi: 10.1111/pops.12056

Postle, B. R. (2015). Essentials of cognitive neuroscience. John Wiley \& Sons, Ltd.

Rouder, J. N \& King, J. W. (2003). Flanker and negative flanker effects in letter identification. Perception $\mathcal{E}$ Psychophysics, 65(2), 287-297.

Stins, J, F., Polderman, J. C. T., Boomsma, D. I. \& Geus, E. J. C. (2007). Conditional accuracy in response interference tasks: Evidence from the
Eriksen flanker task and the spatial conflict task. Advances in Cognitive Psychology, 3(3), 409-417. doi: 10.2478/v10053-0080005-4

Shiraev, E. B \& Levy, D. A. (2010). Crosscultural psychology-critical thinking and contemporary applications. Pearson Education, Inc.

Ryan, R. (2009). Self determination theory and wellbeing. Journal of WeD Research Review, 1, 1-2.

Wells, I. C. \& Hamm, J. P. (2009). The effect of inverting stimuli in a flanker task. Canadian Journal of Experimental Psychology, 63(1), 33-39. doi: 10.1037/ a0013440.

Wright, J. D. (2015). International encyclopedia of the social and behavioral sciences - second edition. Elsevier Ltd.

Wylie, S. A., van den Wildenberg, W. P. M., Ridderinkhof, K. R., Bashore, T. R., Powell, V. D., Manning, C. A., \& Wooten, G. F. (2009). The effect of speed-accuracy strategy on response interference control in Parkinson's diseases. Neuropsychologia, 47(0), 18441853.

doi: $\underline{10.1016 / j . n e u r o p s y c h o l g i a .2009 .02 .025}$

Zhou, P. \& Liu, X. (2013). Attentional modulation of emotional conflict processing with flanker tasks. PLoS ONE, 8(3), 1-8. doi: 10.1371/journal.pone.0060548

Zhu, Y. Zhou, Q. \& Ye, X,D. (2016). Competing with visible and invisible competitors in flanker tasks. Social behavior and personality, 44(11), 18151824.

http://doi.org/0.2224/sbp.2016.44.11.18 15 